\title{
Detection of chlorophyll and leaf area index dynamics from sub-weekly hyperspectral imagery
}

\author{
Rasmus Houborg*a, Matthew F. McCabe ${ }^{\mathrm{a}}$, Yoseline Angel ${ }^{\mathrm{a}}$, Elizabeth M. Middleton ${ }^{\mathrm{b}}$ \\ ${ }^{a}$ King Abdullah University of Science and Technology (KAUST), Water Desalination and Reuse \\ Center (WDRC), Biological and Environmental Science \& Engineering (BESE), Saudi Arabia \\ ${ }^{b}$ NASA Goddard Space Flight Center (GSFC), Greenbelt, Maryland, U.S.A
}

\begin{abstract}
Temporally rich hyperspectral time-series can provide unique time critical information on within-field variations in vegetation health and distribution needed by farmers to effectively optimize crop production. In this study, a dense timeseries of images were acquired from the Earth Observing-1 (EO-1) Hyperion sensor over an intensive farming area in the center of Saudi Arabia. After correction for atmospheric effects, optimal links between carefully selected explanatory hyperspectral vegetation indices and target vegetation characteristics were established using a machine learning approach. A dataset of in-situ measured leaf chlorophyll $\left(\mathrm{Chl}_{1}\right)$ and leaf area index (LAI), collected during five intensive field campaigns over a variety of crop types, were used to train the rule-based predictive models. The ability of the narrow-band hyperspectral reflectance information to robustly assess and discriminate dynamics in foliar biochemistry and biomass through empirical relationships were investigated. This also involved evaluations of the generalization and reproducibility of the predictions beyond the conditions of the training dataset. The very high temporal resolution of the satellite retrievals constituted a specifically intriguing feature that facilitated detection of total canopy Chl and LAI dynamics down to sub-weekly intervals. The study advocates the benefits associated with the availability of optimum spectral and temporal resolution spaceborne observations for agricultural management purposes.
\end{abstract}

Keywords: LAI, Total canopy chlorophyll, Cubist, Hyperion, Hyperspectral, Dryland, Vegetation indices

\section{INTRODUCTION}

Enhancements in the spectral, spatial and temporal resolution of space observations have significantly advanced the capacity to monitor and model the state and function of vegetation canopies ${ }^{1}$. Hyperspectral sensing (i.e., involving data acquisition in several narrow $(<10 \mathrm{~nm})$ contiguous spectral bands) has proven particularly useful for quantifying plant pigments $^{2,3}$, assessing crop growth and vegetation density ${ }^{4,5}$, crop type discrimination ${ }^{6}$, and monitoring of light-useefficiency and plant productivity ${ }^{7}$, using unique spectral features in narrow bands distributed across the electromagnetic spectrum. The same retrieval robustness and capability is rarely achievable by standard broadband multi-spectral systems such as Landsat due to limitations in the spectral information content ${ }^{8}$. However the advancement of hyperspectral techniques for vegetation monitoring and characterization over space and time domains has been hindered by the lack of an operational hyperspectral satellite mission distributing high-resolution data over the entire surface of the earth.

Hyperion onboard the Earth Observing-1 (EO-1) satellite launched in 2000 represents the first spaceborne hyperspectral imager that remains in operation to this day despite an impressive 15 years of operation. Hyperion has made important contributions to the advancement of science and has been instrumental in the development of future global imaging spectrometers ${ }^{9}$. The availability of repeatable high spatial resolution (i.e., $30 \mathrm{~m}$ ) imagery over large regions is constrained by its revisit capability and narrow scene swaths $(\sim 7.5 \mathrm{~km})$, which limit acquisitions to relatively few target sites via the instruments tasking capability. The frequency and large area availability of hyperspectral observations will improve substantially with the prospective launch of the Environmental Mapping and Analysis Program (ENMAP; www.enmap.org) hyperspectral satellite mission in 2018, and the Hyperspectral Infrared Imager (HyspIRI; https://hyspiri.jpl.nasa.gov) around 2022. ENMAP will provide full spectrum (420 to $2450 \mathrm{~nm})$ data in $30 \mathrm{~km}$ swaths at $30 \mathrm{~m}$ resolution over a globally distributed network of regional target sites with a 4-day revisit frequency by exploiting the off-nadir $\left( \pm 30^{\circ}\right)$ pointing capability ${ }^{10}$. The wider scene swath (i.e., $150 \mathrm{~km}$ ) of HyspIRI would ensure a global revisit of 19 days. If realized, these initiatives would constitute a hyperspectral revolution with far reaching opportunities for

*rasmus.houborg@kaust.edu.sa; phone 966 544700262; hydrology.kaust.edu.sa

Remote Sensing for Agriculture, Ecosystems, and Hydrology XVIII, edited by

Christopher M. U. Neale, Antonino Maltese, Proc. of SPIE Vol. 9998, 999812

(C) 2016 SPIE · CCC code: $0277-786 X / 16 / \$ 18 \cdot$ doi: $10.1117 / 12.2241345$

Proc. of SPIE Vol. $9998999812-1$ 


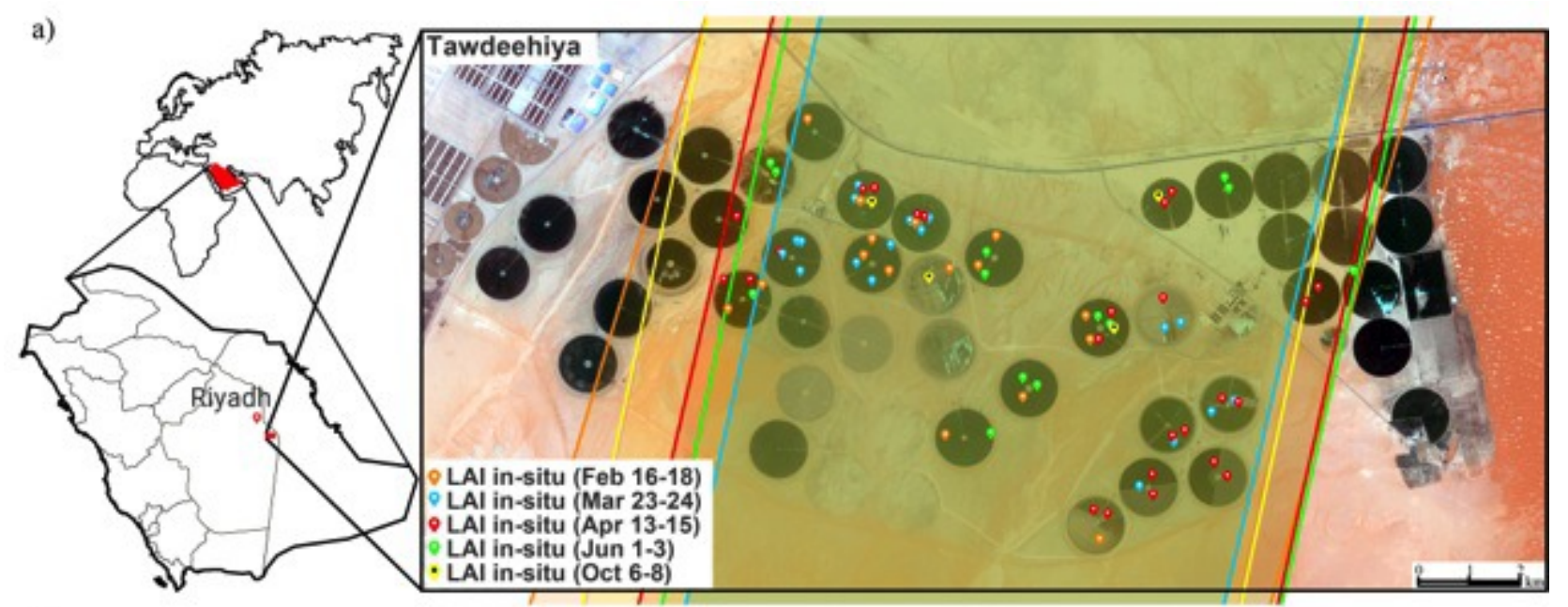

b)

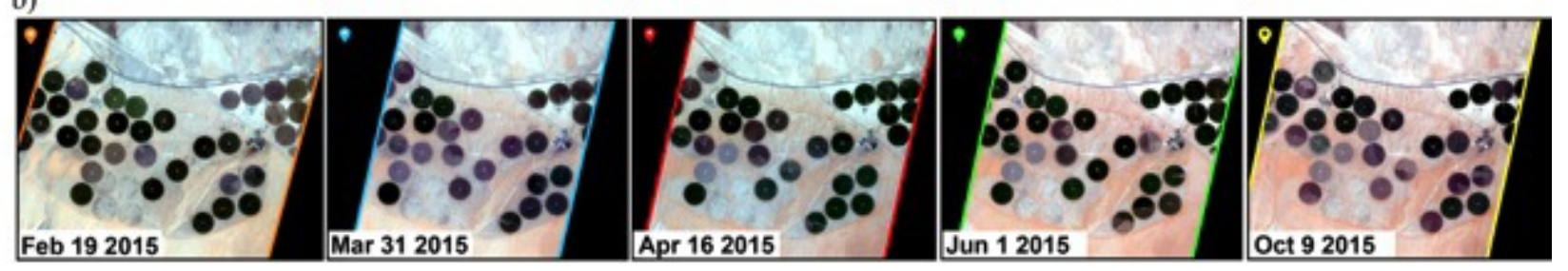

Figure 1. (a) The Tawdeehiya farm in Saudi Arabia with indication of sites with intensive measurements during the five field campaigns in 2015. The background image is a natural color representation of $5 \mathrm{~m}$ resolution RapidEye data collected on May $31^{\mathrm{st}}$. (b) Natural color (RGB) representations of the five Hyperion images collected in proximity to the field campaigns. The changing viewing geometry of the acquisitions (see Table 1) result in variations in the farm coverage as indicated in (a).

high spatial resolution vegetation monitoring ${ }^{1}$. Hyperion remains attractive as a preparatory platform for researching and demonstrating the enhanced utility to be offered by these future hyperspectral sensing platforms ${ }^{11,12}$.

With the exciting prospect of a substantial increase in the availability and frequency of hyperspectral imagery in the near future, the development of advanced techniques to fully utilize the vast information content present in hyperspectral data streams is imminent. In this contribution, high frequency Hyperion images acquired over an intensive farming site in the desert of Saudi Arabia (see Figure 1) were used to infer the spatial and temporal dynamics in leaf area index (LAI) and total canopy chlorophyll (TChl) based on an empirical data mining approach. The availability of hyperspectral observations at both high spatial $(30 \mathrm{~m})$ and high temporal ( $\sim$ weekly) resolution over an extended period is unique and an opportunity to investigate the benefits of a near-optimum resolution (i.e., spectral, spatial, and temporal) dataset for monitoring vegetation health and growth at sub-field scales.

\section{MATERIAL AND METHODS}

\subsection{Study site}

The Hydrology, Agriculture and Land Observation (HALO) group at King Abdullah University of Science and Technology (hydrology.kaust.edu.sa) has established a state-of-the-art observatory at the Tawdeehiya Arable Farm $\left(24.174{ }^{\circ} \mathrm{N}, 48.015^{\circ} \mathrm{E}\right)$ located in a desert region southeast of the capitol Riyadh in Saudi Arabia (Figure 1). Flux and meteorological towers have been deployed at the farm and ancillary information on soil and vegetation characteristics are collected regularly during intensive field campaigns. The farm operates center-pivot irrigation systems on 47 fields that grow alfalfa, Rhodes grass, maize, or vegetables. The climate is arid with the bulk of the annual precipitation $(\sim 95 \mathrm{~mm})$ concentrated between the months of December through April ${ }^{13}$. Despite a predominance of clear skies, desert dust and relatively strong winds often result in hazy field conditions ${ }^{14}$. 
Table 1. Dates of the field campaigns, number of in-situ samples (n), and the average values (and stddev) of LAI and Chl during each campaign. Characteristics associated with the Hyperion scenes acquired within a few days (HYP DOY) of the field campaign dates are also given.

\begin{tabular}{|c|c|c|c|c|c|c|c|c|c|c|c|}
\hline $\begin{array}{l}\text { Campaign dates } \\
\text { (2015) }\end{array}$ & DOY & n & LAI & $\mathrm{Chl}_{\mathbf{l}}$ & $\begin{array}{l}\text { HYP } \\
\text { DOY }\end{array}$ & Time & $\tau_{550}$ & $\begin{array}{l}\boldsymbol{\theta}_{\mathbf{s z}} \\
{\left[{ }^{\circ}\right]}\end{array}$ & $\begin{array}{l}\boldsymbol{\theta}_{\mathrm{vz}} \\
{\left[{ }^{\circ}\right]}\end{array}$ & $\begin{array}{l}\theta_{\mathrm{saz}} \\
{\left[{ }^{\circ}\right]}\end{array}$ & $\begin{array}{l}\theta_{\text {sataz }} \\
{\left[{ }^{\circ}\right]}\end{array}$ \\
\hline Feb 16-18 28 & $47-49$ & $16 / 15$ & $1.9 \pm 1.1$ & $60 \pm 16$ & 50 & $9: 15$ & 0.13 & 54.0 & 26.4 & 126.4 & 98.0 \\
\hline March 23-24 & $82-83$ & $18 / 17$ & $3.6 \pm 0.9$ & $54 \pm 20$ & 90 & $8: 55$ & 0.41 & 47.1 & 6.0 & 108.2 & 278.0 \\
\hline April 13-15 & $103-105$ & $25 / 19$ & $2.8 \pm 1.8$ & $43 \pm 18$ & 106 & $8: 46$ & 0.58 & 45.4 & 20.5 & 100.2 & 278.0 \\
\hline June 1-3 & $152-154$ & $13 / 13$ & $4.2 \pm 1.3$ & $46 \pm 9$ & 152 & $8: 43$ & 0.31 & 41.7 & 18.2 & 83.5 & 278.0 \\
\hline Oct 6-8 & $279-281$ & $4 / 3$ & $2.6 \pm 1.9$ & $51 \pm 13$ & 282 & $8: 29$ & 0.40 & 54.5 & 21.9 & 117.6 & 278.0 \\
\hline
\end{tabular}

\subsection{In-situ measurements}

This study used data collected during five field campaigns (Table 1). Measurements of leaf area index (LAI), defined as one-sided green leaf area per unit horizontal ground area $\left[\mathrm{m}^{-2} \mathrm{~m}^{-2}\right]$, and leaf chlorophyll $\left(\mathrm{Chl}_{1}\right)$, defined as the total chlorophyll $a$ plus chlorophyll $b$ content on a one-sided leaf area basis $\left[\mu \mathrm{g} \mathrm{cm}{ }^{-2}\right]$, were conducted within rectangular sampling units $(30 \times 30 \mathrm{~m})$ comprised of 13 measurement plots. The measurement at each plot was averaged to produce a representative value for the specific sampling unit. A total of 76 (LAI) and $67\left(\mathrm{Chl}_{1}\right)$ samples were collected over the duration of the five campaigns (Table 1) within the domain of the satellite acquisitions (Figure 1). LAI was measured on clear days with a LAI-2200C plant canopy analyzer (LICOR, U.S.A) and corrected for light scattering ${ }^{14}$. Chl $l_{1}$ was measured near-simultaneously with a portable SPAD-502 meter (Konica Minolta, Inc., Osaka, Japan), except in the carrot fields where the leaves were too narrow to accurately measure $\mathrm{Chl}_{1}$. The detailed measurement protocol and conversion of the SPAD units to leaf chlorophyll content $\left[\mu \mathrm{g} \mathrm{cm}^{-2}\right]$ is described in Houborg and McCabe ${ }^{14}$. Total canopy chlorophyll (TChl) in units of $\mathrm{g} \mathrm{m}^{-2}$ was derived by multiplication of Chl with LAI and division by 100 .

\subsection{HYPERION data}

The Hyperion hyperspectral imager is part of the Earth Observing-1 (EO-1) satellite mission launched in November $2000^{9}$. Hyperion acquires continuous narrow-band $(10 \mathrm{~nm})$ data over the visible to shortwave infrared domain (400 to $2500 \mathrm{~nm}$ ), providing 196 calibrated spectral bands with a $30 \mathrm{~m}$ nadir ground resolution. Hyperion data collections are programmable which facilitates targeted and potentially frequent monitoring in narrow swaths (Figure 1). The off-nadir viewing capability (i.e., $\pm 22^{\circ}$ roll angle) facilitates up to five image acquisitions during a 16-day period ${ }^{15}$. For the present study, a total of 42 scenes were acquired over the Tawdeehiya farm during 2015. The imagery is provided radiometrically corrected in at-sensor radiance units and has been resampled for geometric correction and georeferenced using a digital elevation model ${ }^{16}$. Atmospheric correction to surface reflectance was performed using the Fast Line-ofSight Atmospheric Analysis of Spectral Hypercubes (FLAASH) algorithm ${ }^{17,18}$. Precipitable water vapor was retrieved using bands around the $1135 \mathrm{~nm}$ water vapor band and information on aerosol optical depth at $550 \mathrm{~nm}\left(\tau_{550}\right)$, was acquired from the Terra MODIS aerosol product (MOD04). The atmospheric correction also included corrections for adjacency effects, which are particularly important for high spatial resolution observations in regions with large contrasts in surface reflectance ${ }^{19}$. The horizontal range of the adjacency effect was defined via an aerosol scale height of $2 \mathrm{~km}$. Finally minimum noise fraction transformation ${ }^{20}$ was applied to reduce striping effects and smooth reflectance profiles.

Each of the intensive field campaigns was associated with a satellite acquisition within a few days of the in-situ observations (Figure 1 and Table 1). Hyperion acquisitions occur in the mornings (around 9 am) and image capture may occur in both forward and back scattering directions with variable viewing angles (Table 1). 
Table 2. List of vegetation indices (VI) used as explanatory variables in the Cubist regression modeling. The band designations of the original indices have been adjusted to match the center bandwidths of the $10 \mathrm{~nm}$ wide Hyperion sensor bands. The first 12 VIs represent Landsat-like indices.

Name

Vegetation index

Reference

Normalized Difference Vegetation Index

$N D V I=\left(R_{872}-R_{661}\right) /\left(R_{872}+R_{661}\right)$

Enhanced Vegetation Index

$E V I=2.5 \cdot \frac{R_{872}-R_{661}}{R_{872}+6 \cdot R_{661}-7.5 \cdot R_{488}+1}$

Soil Adjusted Vegetation Index

$S A V I=\left[1.5 \cdot\left(R_{872}-R_{661}\right)\right] /\left(R_{872}+R_{661}+0.5\right)$

Non-Linear Index

Simple Ratio

Renormalized Difference Vegetation Index

$N L I=\left(R_{872}^{2}-R_{661}\right) /\left(R_{872}^{2}+R_{661}\right)$

$S R=R_{872} / R_{661}$

$R N D V I=\left(R_{872}-R_{661}\right) /\left(\sqrt{\left(R_{872}+R_{661}\right)}\right)$

Green Normalized Difference Vegetation Index

$G N D V I=\left(R_{872}-R_{559}\right) /\left(R_{872}+R_{559}\right)$

Green Ratio Vegetation Index

$G R V I=R_{872} / R_{559}$

Modified Triangular Vegetation Index - Improved

MTVI2 $=\frac{1.5\left[1.2\left(R_{803}-R_{549}\right)-2.5\left(R_{671}-R_{549}\right)\right]}{\sqrt{\left(2 \cdot R_{803}+1\right)^{2}-\left(6 \cdot R_{803}-5 \cdot \sqrt{R_{671}}\right)-0.5}} \quad 4$

Atmospherically Resistant Vegetation Index

$A R V I=\frac{R_{872}-\left[R_{661}-\left(R_{488}-R_{661}\right)\right]}{R_{872}+\left[R_{661}-\left(R_{488}-R_{661}\right)\right]}$

$G A R I=\frac{R_{872}-\left[R_{559}-\left(R_{488}-R_{661}\right)\right]}{R_{872}+\left[R_{559}-\left(R_{488}-R_{661}\right)\right]} \quad 30$

Green Atmospherically Resistant Index

Visible Atmospherically Resistant Index

Modified Chlorophyll Absorption Ratio Index

Modified Chlorophyll Absorption Ratio Index Improved

Red Edge Normalized Difference Vegetation Index

Modified Red Edge Normalized Difference

Vegetation Index

Red-edge Simple Ratio

Vogelmann Red Edge Index 1

Vogelmann Red Edge Index 2

Photochemical Reflectance Index

Structure Insensitive Pigment Index

MERIS Terrestrial Chlorophyll Index

Anthocyanin Reflectance Index 2

Carotenoid Reflectance Index 1

Carotenoid Reflectance Index 2

Red Green Ratio Index 


\subsection{Cubist regression approach}

Empirical associations between target vegetation characteristics (i.e., LAI and TChl) measured in-situ and the Hyperion spectral observations were established on the basis of the Cubist (RuleQuest; www.rulequest.com) data mining technique. Cubist adopts a model tree approach ${ }^{42,43}$ for building a set of rules each represented by a multi-variate linear regression model. The LAI and TChl predictive models were trained on the basis of the in-situ collected data paired with explanatory data values from a wide range of Vegetation Indices (VIs) extracted from the hyperspectral imagery at each sampling unit. The squared form of each VI was also added as input to the model training. The list of selected VIs (Table 2) encompasses indices previously reported in the literature and with known sensitivities to the target variables. The band designations of the original indices were adjusted to conform to the center bandwidths of the $10 \mathrm{~nm}$ wide Hyperion bands (Table 2).

The benefit of Cubist lies in its ability to efficiently identify and organize the optimal combination of VIs in a set of rules based on a large training dataset. The full training dataset was used to build the predictive regression models that were subsequently applied to the full suite of Hyperion images in order to map LAI and TChl over the duration of the study period. Given the fairly limited number of in-situ sampling units (Section 2.2), the number of maximum rules was set to 2. This will reduce the risk of disrupting the spatial value continuity in LAI and TChl when applying the models on unseen data ${ }^{44}$. Model regressions were also constructed using standard Landsat-like VIs (i.e., the first 12 indices in Table 2 ) as input to Cubist. These were constructed using the Hyperion bands that most closely match the band designations of the Landsat- 8 blue $(488 \mathrm{~nm})$, green $(559 \mathrm{~nm})$, red $(661 \mathrm{~nm})$, and near-infrared $(872 \mathrm{~nm})$ bands. The results of these model predictions were compared to the results utilizing the full suite of VIs (Table 2) in order to investigate the potential benefit of the enhanced hyperspectral information content for characterizing vegetation canopies. The predictabilities were assessed using standard statistics including the coefficient of determination $\left(\mathrm{R}^{2}\right)$, and the relative Mean Absolute Deviation (MAD) and Mean Bias Deviation (MBD) calculated by diving the deviations with the mean of the in-situ measurements.

\section{RESULTS AND DISCUSSION}

\subsection{Cubist regression results}

For LAI, Cubist defined two separate model regressions (i.e., rules) for describing the variability of the in-situ LAI observed during the five campaigns (LAI ranging between 0 and $5.87 \mathrm{~m}^{2} \mathrm{~m}^{-2}$ ):

$$
\begin{gathered}
L A I=-0.1547642+50.5 \cdot S A V I^{2}+26.58 \cdot N D V I^{2} \\
L A I=-1.2568875+44.1 \cdot S A V I^{2}-22.3 \cdot G N D V I^{2}-14.9 \cdot M T V I 2^{2}+6.62 \cdot N L I \\
+3.52 \cdot V R E I 1^{2}-7.61 \cdot N D V I^{2}-8.8 \cdot V A R I+27 \cdot P R I^{2}
\end{gathered}
$$

The first model is used when SAVI $\leq 0.213$ (i.e., low vegetation densities) and incorporates normalized difference VIs (i.e., NDVI, SAVI) based on standard bands in the red and near-infrared domain (Table 2). The second model is used when SAVI $>0.213$ and also includes a simple ratio (i.e., VREI1) based on bands in the red-edge region, in addition to the normalized difference between leaf reflectance on either side of the green reflectance peak (i.e., PRI) (Table 2). The rededge is highly sensitive to variations in LAI and has shown to provide improved predictability over dense vegetation ${ }^{5,14}$. The PRI signal responds to vegetation stress and correlates with the efficiency of photosynthetic activity ${ }^{45}$, which will be related to the greenness, health and density of the vegetation canopy. These hyperspectral models yield an $\mathrm{R}^{2}$ of 0.94 and a relative MAD of $10.4 \%$ when using the same dataset for training and validation (Figure 2a). The level of agreement decreases $\left(\mathrm{R}^{2}=0.89, \mathrm{MAD}=14.6 \%\right)$ when only Landsat-like VIs are used in Cubist (Figure $\left.2 \mathrm{~b}\right)$. With that setup, Cubist also defined two rules (with similar rule conditions as stated for Eq. 1 and 2), combining SAVI, NDVI, EVI and NDVI in rule 1, and GARI, ARVI, VARI, NDVI, EVI, GNDVI and GRVI in rule 2 (not shown).

The resulting model regressions for TChl, based on the full spectrum suite of VIs, predominantly consist of indices using bands in the red-edge region (i.e., VREI1, RSR, RENDVI, MRENDVI, MCARI, CRI2):

$$
\begin{gathered}
T C h l=10.57968+11.51 \cdot V R E I 1^{2}-24.52 \cdot V R E I 1-0.8 \cdot R S R^{2}+0.482 \cdot S R+4.53 \cdot R G R I+7.39 \cdot R N D V I^{2} \\
-1.7 R G R I^{2}-2.17 \cdot R E N D V I-1.63 \cdot M R E N D V I^{2}+1.46 \cdot E V I-129.34 \cdot M_{C A R I}^{2}
\end{gathered}
$$




$$
\begin{aligned}
\text { TChl }= & 35.14363-41.49 \cdot V R E I 1+14.97 \cdot V R E I 1^{2}+13.8 \cdot R G R I^{2}-20.42 \cdot R G R I \\
& +13.01 \cdot R N D V I^{2}-0.00357 \cdot C R I 2^{2}-0.291 \cdot R S R^{2}-31.88 \cdot M C A R I^{2}
\end{aligned}
$$

These rules are valid over the observed range in TChl ( 0 to $\left.3.6 \mathrm{~g} \mathrm{~m}^{-2}\right)$. Rule one (Eq. 3$)$ is used when RGRI $>1.173$ whereas rule two (Eq. 4) applies when RGRI $\leq 1.173$. Verification against the training data yields an $\mathrm{R}^{2}$ of 0.83 and a relative MAD of $22 \%$ (Figure $2 \mathrm{c}$ ). When the spectral information is reduced to the Landsat-like VIs, the majority of the in-situ data points are defined by a single rule that relies on indices based on the green band (i.e., GARI, ARVI, VAI, GNDVI, GRVI) in addition to indices responding predominantly to vegetation density (i.e., NDVI, EVI). While the green band contains valuable information for the assessment of chlorophyll dynamics ${ }^{34,46}$, red-edge information is recognized as key for improving the robustness of chlorophyll retrieval ${ }^{47,48}$ due to enhanced sensitivity at high ranges and lower atmospheric correction uncertainties ${ }^{14}$. Accordingly, validation results based solely on the Landsat-like VIs yield a reduced correlation $\left(\mathrm{R}^{2}=0.69\right)$ and a higher MAD (26.8\%) (Figure 2d). As demonstrated above, the enhanced hyperspectral information content serves to more robustly reproduce the LAI and TChl dynamics observed during the five field campaigns (Figure 2).
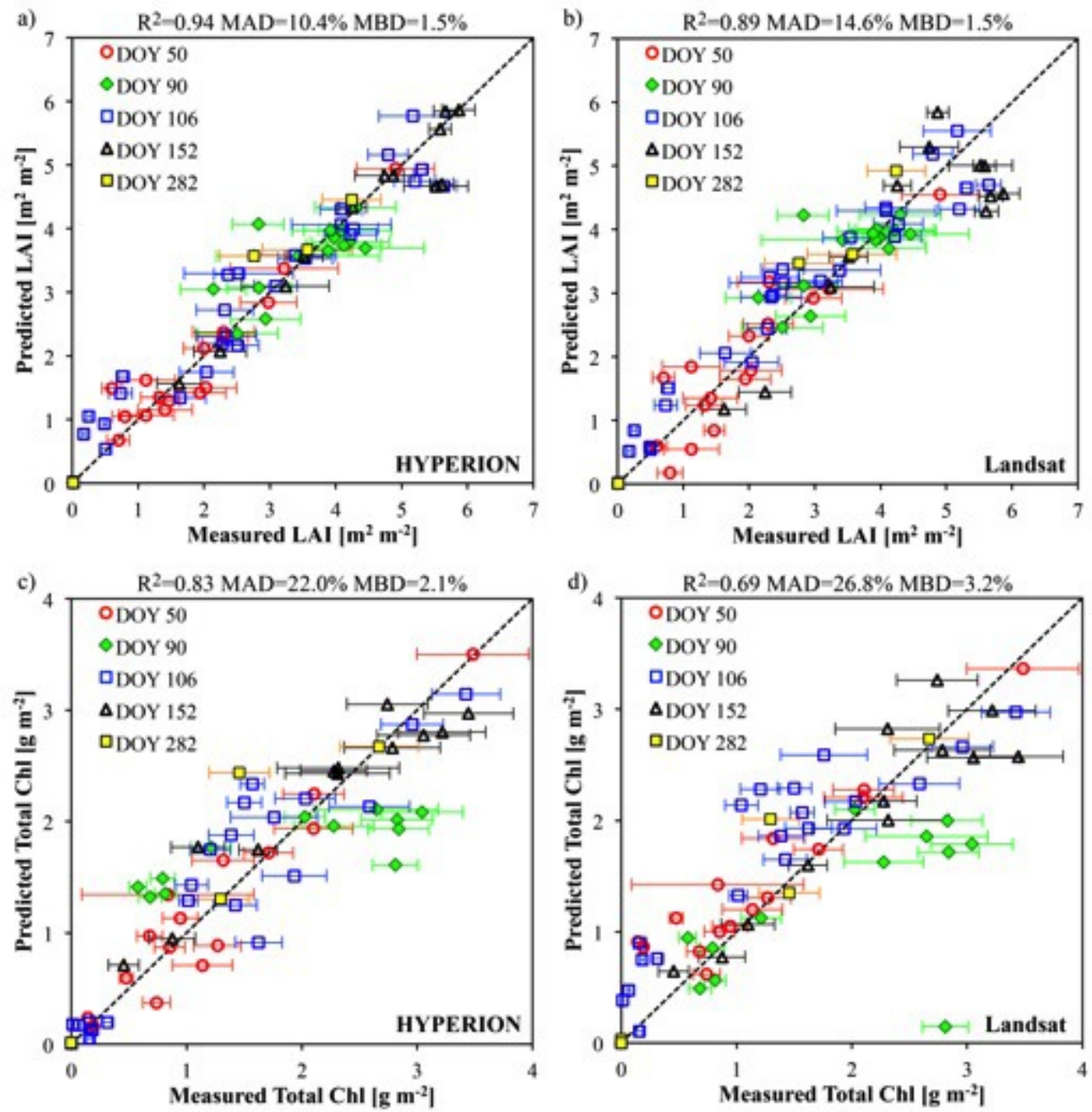

Figure 2. Validation of the Cubist-based LAI $(a, b)$ and TChl $(c, d)$ predictions against the in-situ observations (the error bars represent the stddev of the measurements within each sampling unit). In (a) and (c) the full suite of hyperspectral VIs (Table 2) was used as input to Cubist. In (b) and (d) only Landsat-like VIs were used as input to Cubist. The model performance is indicated by standard statistic metrics. 


\subsection{Time-series of LAI and TChl}

The model regressions described and validated above (Eq. 1 to 4) were applied to the full suite of available Hyperion images. Figure 3a showcases resulting spatial features in LAI and TChl for a single Hyperion acquisition whereas Figure $3 \mathrm{~b}$ (middle and bottom panels) demonstrates the temporal dynamics for three crop-specific (i.e., alfalfa, maize, grass) pixel locations. The overall spatial features in LAI and TChl are similar with dense crop pivots generally associated with the highest canopy chlorophyll contents (Figure 3a). However the magnitudes in TChl may differ significantly between crop classes as a result of variations in the characteristic leaf chlorophyll $\left(\mathrm{Chl}_{1}\right)$ level of each crop species. For instance, the Rhodes grass fields at the farm (e.g. P3) have substantially lower Chl values than the alfalfa fields (e.g. P1) ${ }^{14}$, which result in large differences in the TChl level between the densely vegetated grass and alfalfa pivots (Figure 3a). Variations in the behavior of LAI and TChl are also evident at the sub-field scale, which may result from intra-field variations in growing conditions (e.g., nutrients and water availability, plant physiological condition and photosynthetic performance) that will affect the canopy density and leaf chlorophyll content differently ${ }^{49}$.

The LAI time-series demonstrate the characteristic phenology of alfalfa (P1) with multiple relatively short growing cycles and an abrupt decline due to harvest at peak vegetation densities (Figure 3b). The harvest and re-growth of the alfalfa crop is not captured by the satellite imagery between DOY 180 and 208 due to a pause in the tasked acquisitions

a)
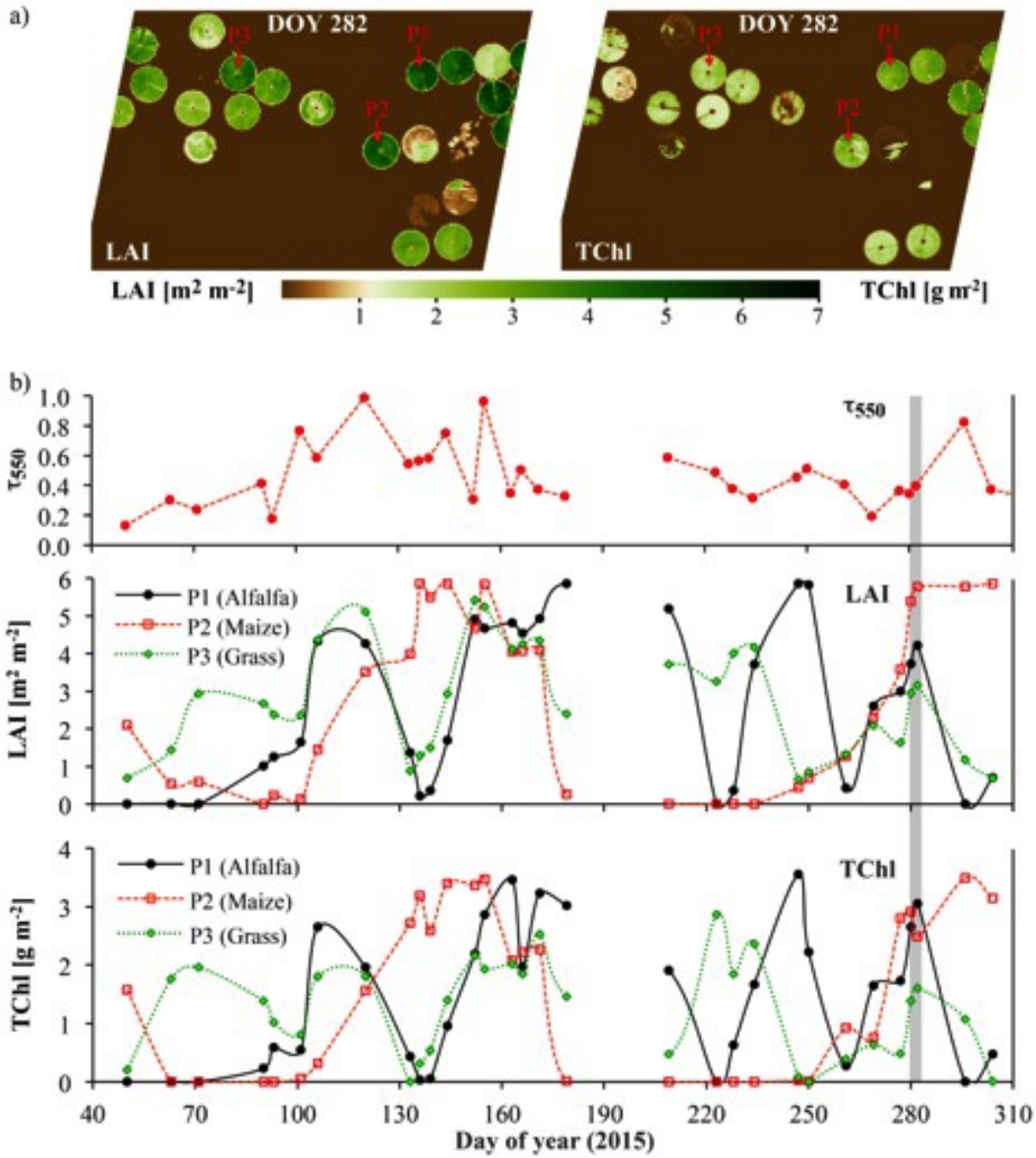

Figure 3. (a) LAI and TChl predictions on DOY 282 based on Eq. 1 - 4. (b) Time-series of scene-wide MODIS-derived $\tau_{550}$ (top panel), and Hyperion-based LAI (middle panel) and TChl (bottom panel) for selected pixel locations. 
during this time interval. Maize (P2) is characterized by two growing cycles with planting dates in the early spring and early fall, respectively (Figure 3b). Maize is harvested before senescence sets in as evidenced by the sharp decline in LAI between DOY 171 and 179. The phenology of the grass field (P3) indicates multiple growing cycles similar to alfalfa, but the harvesting schedule varied and the activity of the grass center-pivot irrigation system was significantly more sporadic over the course of the field campaigns ${ }^{14}$. The TChl and LAI temporal dynamics are strongly associated, particularly over the alfalfa $\left(\mathrm{R}^{2}=0.88\right)$ and maize $\left(\mathrm{R}^{2}=0.94\right)$ pixel locations, which are expected in fields with sufficient water and nutrient availability ${ }^{50}$. The inter-correlation is lower for the grass location $\left(\mathrm{R}^{2}=0.64\right)$, which may be the result of non-optimal growing conditions during periods with sporadic activity of the irrigation system.

The time-series of both LAI and TChl sometimes depict unrealistic behavior, which may result from uncertainties introduced by the atmospheric correction process, view-angle effects from the use of off-nadir Hyperion acquisitions ${ }^{51}$, and issues related to the transferability of empirically based model regressions ${ }^{52}$. While the spectral stability of Hyperion surface reflectance time-series has been shown to consistently range between $2.5-5 \%^{12}$, the atmospheric correction is particularly challenged over these dryland agricultural regions due to high aerosol loadings (Figure $3 \mathrm{~b}$ ) and substantial adjacency effects resulting from high contrast surface reflectance surfaces (i.e., bright desert versus dark vegetated surfaces) ${ }^{14}$. These issues will need further consideration in order to accurately detect subtle temporal dynamics in LAI and chlorophyll from sub-weekly Hyperion acquisitions.

\section{CONCLUSIONS}

Hyperspectral sensing offers significant potential for advancing the capacity to retrieve vegetation characteristics through novel uses of the vast spectral information content. This study demonstrated the utility of a unique high-frequency timeseries of Hyperion images for leaf area index (LAI) and total canopy chlorophyll (TChl) estimation over a dryland agricultural landscape. A data mining approach was used to establish optimal links between in-situ measurements of the target variables and a wide range of explanatory hyperspectral vegetation indices. The established multi-variate model regressions provided robust assessments of the dynamics in LAI and TChl observed over five intensive field campaigns, and out-performed the predictability achieved when only Landsat-like vegetation indices were used to train the regression models. Application of the developed models to the full suite of Hyperion images realistically reproduced the general phenological features of the dominant crops. However the detection of more subtle spatial and temporal dynamics resulting from short-term variations in vegetation condition remains a key challenge due to uncertainties introduced by the atmospheric correction and significant sensor view-angle effects. In addition, the validity of the empirical regressions beyond the training data will need further investigation. A key objective of ongoing work is to fully utilize the rich information content of the hyperspectral data streams by complementing the existing list of explanatory spectral indices (Table 2) with additional hyperspectral metrics, such as those based on continuum removal $^{12,53,54}$.

\section{ACKNOWLEDGEMENTS}

Research reported in this publication was supported by the King Abdullah University of Science and Technology (KAUST). We greatly appreciate the logistical, equipment and scientific support offered to our team by Mr Jack King, Mr Alan King and employees of the Tawdeehiya Farm in Al Kharj, Saudi Arabia, without whom this research would not have been possible.

\section{REFERENCES}

[1] Houborg, R., Fisher, J. B., Skidmore, A. K., “Advances in remote sensing of vegetation function and traits,” Int. J. Appl. Earth Obs. Geoinf. 3, 1-6 (2015).

[2] Curran, P. J., "Remote Sensing of Foliar Chemistry," Remote Sens. Environ. 30(3), 271-278 (1989).

[3] Blackburn, G. A., "Hyperspectral remote sensing of plant pigments.," J. Exp. Bot. 58(4), 855-867 (2007).

[4] Haboudane, D., "Hyperspectral vegetation indices and novel algorithms for predicting green LAI of crop canopies: Modeling and validation in the context of precision agriculture," Remote Sens. Environ. 90(3), 337- 
$352(2004)$.

[5] Viña, A., Gitelson, A. A., Nguy-Robertson, A. L., Peng, Y., "Comparison of different vegetation indices for the remote assessment of green leaf area index of crops," Remote Sens. Environ. 115(12), 3468-3478 (2011).

[6] Mariotto, I., Thenkabail, P. S., Huete, A., Slonecker, E. T.., Platonov, A., "Hyperspectral versus multispectral crop-productivity modeling and type discrimination for the HyspIRI mission," Remote Sens. Environ. 139, 291305 (2013).

[7] Penuelas, J., Garbulsky, M. F., Filella, I., "Photochemical reflectance index (PRI) and remote sensing of plant CO2 uptake," New Phytol., 1-4 (2011).

[8] Ustin, S. L., Roberts, D. A. R. A., Gamon, J. A., Green, R. O., "Using Imaging Spectroscopy to Study Ecosystem Processes and Properties," Bioscience 54(6), 523-534 (2004).

[9] Middleton, E. M., Ungar, S. G., Mandl, D. J., Ong, L., Frye, S. W., Campbell, P. E., Landis, D. R., Young, J. P.., Pollack, N. H., "The earth observing one (EO-1) satellite mission: Over a decade in space," IEEE J. Sel. Top. Appl. Earth Obs. Remote Sens. 6(2), 243-256 (2013).

[10] Kaufmann, H., Förster, S., Wulf, H., Segl, K., Guanter, L., Bochow, M., Heiden, U., Müller, A., Heldens, W., Schneiderhan, T., Leitão, P. J., van der Linden, S., Hostert, P., Hill, J., Buddenbaum, H., Mauser, W., Hank, T., Krasemann, H., Röttgers, R., Opp, B., "Science Plan of the Environmental Mapping and Analysis Program (EnMAP)," 65 (2012).

[11] Christian, B., Joshi, N., Saini, M., Mehta, N., Goroshi, S., Nidamanuri, R. R., Thenkabail, P., Desai, A. R., Krishnayya, N. S. R., "Seasonal variations in phenology and productivity of a tropical dry deciduous forest from MODIS and Hyperion," Agric. For. Meteorol. 214-215, 91-105 (2015).

[12] Campbell, P. K. E., Middleton, E. M., Thome, K. J., Kokaly, R. F., Huemmrich, K. F., Lagomasino, D., Novick, K. A., Brunsell, N. A., "EO-1 hyperion reflectance time series at calibration and validation sites: Stability and sensitivity to seasonal dynamics,” IEEE J. Sel. Top. Appl. Earth Obs. Remote Sens. 6(2), 276-290 (2013).

[13] El Kenawy, A. M., McCabe, M. F., "A multi-decadal assessment of the performance of gauge- and model-based rainfall products over Saudi Arabia: climatology, anomalies and trends,” Int. J. Climatol. 36(2), 656-674 (2016).

[14] Houborg, R., Mccabe, M. F., "Adapting a regularized canopy reflectance model (REGFLEC) for the retrieval challenges of dryland agricultural systems," Remote Sens. Environ. 186, 105-120 (2016).

[15] Folkman, M. A., Pearlman, J., Liao, L. B., Jarecke, P. J., "EO-1/Hyperion hyperspectral imager design, development, characterization, and calibration," Proc. SPIE 4151, 40-51 (2001).

[16] U.S. Geological Survey., "Hyperion Level 1G (L1GST) product output files data format control book (DFCB)" (2006).

[17] Adler-Golden, S. M., Matthew, M. W., Bernstein, L. S., Levine, R. Y., Berk, A., Richtsmeier, S. C., Acharya, P. K., Anderson, G. P., Felde, J. W., et al., "Atmospheric correction for shortwave spectral imagery based on MODTRAN4,” Imaging Spectrom. V 3753(July), 61-69 (1999).

[18] Perkins, T., Adler-Golden, S., Matthew, M. W., Berk, A., Bernstein, L. S., Lee, J., Fox, M., "Speed and accuracy improvements in FLAASH atmospheric correction of hyperspectral imagery,” Opt. Eng. 51(11), 111707 (2012).

[19] Richter, R., Bachmann, M., Dorigo, W.., Muller, A., "Influence of the Adjacency Effect on Ground Reflectance Measurements," IEEE Geosci. Remote Sens. Lett. 3(4), 565-569 (2006).

[20] Green, A. A., Berman, M., Switzer, P., Craig, M. D., “A Transformation for Ordering Multispectral Data in Terms of Image Quality with Implications for Noise Removal,” IEEE Trans. Geosci. Remote Sens. 26(1), 65-74 (1988).

[21] Rouse, J., Haas, R., Schell, J., Deering, D., "Monitoring vegetation systems in the Great Plains with ERTS," Third ERTS-1 Symp. NASA SP-351, 309-317, Washington DC (1973).

[22] Huete, A., Didan, K., Miura, T., Rodriguez, E. P., Gao, X., Ferreira, L. G., "Overview of the radiometric and biophysical performance of the MODIS vegetation indices," Remote Sens. Environ. 83, 195-213 (2002).

[23] Huete, A., “A soil-adjusted vegetation index (SAVI),” Remote Sens. Environ. 25(3), 295-309 (1988).

[24] Goel, N. S., Qin, W., "Influences of canopy architecture on relationships between various vegetation indices and LAI and FPAR: a computer simulation," Remote Sens. Rev. 10(4), 309-347 (1994).

[25] Birth, G. S., McVey, G. R., "Measuring the Color of Growing Turf with a Reflectance Spectrophotometer1," Agron. J. 60, 640-643 (1968).

[26] Roujean, J.-L., Breon, F.-M., "Estimating PAR absorbed by vegetation from bidirectional reflectance measurements," Remote Sens. Environ. 51(3), 375-384 (1995).

[27] Gitelson, A. A.., Merzlyak, M. N., "Remote sensing of chlorophyll concentration in higher plant leaves," Adv. Sp. Res. 22(5), 689-692 (1998). 
[28] Sripada, R. P., Heiniger, R. W., White, J. G.., Meijer, A. D., "Aerial color infrared photography for determining early in-season nitrogen requirements in corn," Agron. J. 98(4), 968-977 (2006).

[29] Kaufman, Y. J., Tanré, D., "Atmospherically Resistant Vegetation Index (ARVI) for EOS-MODIS," IEEE Trans. Geosci. Remote Sens. 30(2), 261-270 (1992).

[30] Gitelson, A. A., Kaufman, Y. J., Merzlyak, M. N., "Use of a green channel in remote sensing of global vegetation from EOS- MODIS," Remote Sens. Environ. 58(3), 289-298 (1996).

[31] Gitelson, A. A., Stark, R., Grits, U., Rundquist, D., Kaufman, Y., Derry, D., "Vegetation and soil lines in visible spectral space: A concept and technique for remote estimation of vegetation fraction," Int. J. Remote Sens. 23(13), 2537-2562 (2002).

[32] Daughtry, C. S. T., Walthall, C. L., Kim, M. S., Colstoun, E. B. de., McMurtrey III, J. E., "Estimating Corn Leaf Chlorophyll Concentration from Leaf and Canopy Reflectance," Remote Sens. Environ. 74, 229-239 (2000).

[33] Sims, D. A., Gamon, J. A., "Relationships between leaf pigment content and spectral reflectance across a wide range of species, leaf structures and developmental stages," Remote Sens. Environ. 81(2), 337-354 (2002).

[34] Gitelson, A. A., Vina, A., Ciganda, V., Rundquist, D. C., Arkebauer, T. J., "Remote estimation of canopy chlorophyll content in crops," Geophys. Res. Lett. 32(8), L08403 (2005).

[35] Vogelmann, J. E., Rock, B. N., Moss, D. M., "Red edge spectral measurements from sugar maple leaves," Int. J. Remote Sens. 14(8), 1563-1575 (1993).

[36] Gamon, J. A., Serrano, L., Surfus, J. S., "The photochemical reflectance index: An optical indicator of photosynthetic radiation use efficiency across species, functional types, and nutrient levels," Oecologia 112(4), 492-501 (1997).

[37] Penuelas, J., Baret, F., Filella, I., "Semi-empirical indices to assess carotenoids/chlorophyll a ratio from leaf spectral reflectance," Photosynthetica 31(2), 221-230 (1995).

[38] Dash, J., Curran, P. J., "The MERIS terrestrial chlorophyll index," Int. J. Remote Sens. 25(23), 5403-5413 (2004).

[39] Gitelson, A. A., Merzlyak, M. N., Chivkunova, O. B., "Optical properties and nondestructive estimation of anthocyanin content in plant leaves," Photochem. Photobiol. 74(1), 38-45 (2001).

[40] Gitelson, A. A., Zur, Y., Chivkunova, O. B., Merzlyak, M. N., "Assessing Carotenoid Content in Plant Leaves with Reflectance Spectroscopy," Photochem. Photobiol. 75(3), 272 (2002).

[41] Gamon, J. A., Surfus, J. S., "Assessing leaf pigment content and activity with a reflectometer," New Phytol. 143(1), 105-117 (1999).

[42] Quinlan, R., "Learning with continuous classes," Proc. 5th Aust. Jt. Conf. Artif. Intell., 343-348 (1992).

[43] Quinlan, R., "Combining instance-based and model-based learning," Proc. Tenth Int. Conf. Mach. Learn., 236243 (1993).

[44] Houborg, R., McCabe, M. F., Gao, F., "A Spatio-Temporal Enhancement Method for medium resolution LAI (STEM-LAI),” Int. J. Appl. Earth Obs. Geoinf. 47, 15-29 (2016).

[45] Gamon, J., Penuelas, J., Field, C., "A Narrow-Waveband Spectral Index That Tracks Diurnal Changes in Photosynthetic Efficiency," Remote Sens. Environ. 41, 35-44 (1992).

[46] Houborg, R., McCabe, M., Cescatti, A., Gao, F., Schull, M., Gitelson, A., "Joint leaf chlorophyll content and leaf area index retrieval from Landsat data using a regularized model inversion system (REGFLEC)," Remote Sens. Environ. 159, 203-221 (2015).

[47] Curran, P. J., Dungan, J. L., Gholz, H. L., "Exploring the relationship between reflectance red edge and chlorophyll content in slash pine," Tree Physiol. 7, 33-48 (1990).

[48] Clevers, J. G. P. W., Gitelson, A. A., "Remote estimation of crop and grass chlorophyll and nitrogen content using red-edge bands on Sentinel-2 and -3," Int. J. Appl. Earth Obs. Geoinf. 23(1), 344-351 (2013).

[49] Houborg, R., Anderson, M. C., Daughtry, C. S. T., Kustas, W. P., Rodell, M., "Using leaf chlorophyll to parameterize light-use-efficiency within a thermal-based carbon, water and energy exchange model," Remote Sens. Environ. 115(7), 1694-1705 (2011).

[50] Gitelson, A. A., Peng, Y., Huemmrich, K. F., "Relationship between fraction of radiation absorbed by photosynthesizing maize and soybean canopies and NDVI from remotely sensed data taken at close range and from MODIS 250m resolution data," Remote Sens. Environ. 147, 108-120 (2014).

[51] Galvão, L. S., Roberts, D. A., Formaggio, A. R., Numata, I., Breunig, F. M., "View angle effects on the discrimination of soybean varieties and on the relationships between vegetation indices and yield using off-nadir Hyperion data," Remote Sens. Environ. 113(4), 846-856 (2009).

[52] Atzberger, C., Darvishzadeh, R., Immitzer, M., Schlerf, M., Skidmore, A., le Maire, G., "Comparative analysis 
of different retrieval methods for mapping grassland leaf area index using airborne imaging spectroscopy,” Int. J. Appl. Earth Obs. Geoinf. 43, 19-31 (2015).

[53] Kokaly, R., Clark, R., "Spectroscopic Determination of Leaf Biochemistry Using Band-Depth Analysis of Absorption Features and Stepwise Multiple Linear Regression," Remote Sens. Environ. 67(3), 267-287 (1999).

[54] Malenovský, Z., Homolová, L., Zurita-Milla, R., Lukeš, P., Kaplan, V., Hanuš, J., Gastellu-Etchegorry, J.-P., Schaepman, M. E., "Retrieval of spruce leaf chlorophyll content from airborne image data using continuum removal and radiative transfer," Remote Sens. Environ. 131, 85-102 (2013). 